\title{
CONECTANDO SABERES NA FORMAÇÃO DOCENTE CAMPESINA EM ESPAÇOS NÃO FORMAIS POR MEIO DO ENSINO DE CIÊNCIAS ${ }^{1}$
}

\author{
Veruschka Silva Santos Melo ${ }^{2}$ \\ Ariadne da Costa Peres Contente ${ }^{3}$
}

\begin{abstract}
RESUMO
O presente artigo almeja compreender como os espaços não formais de ensino podem contribuir para a conexão dos saberes científicos e da tradição para a formação de professores que educam no campo nos anos iniciais de ensino. A partir deste pressuposto busca-se compreender e refletir, por meio de narrativas dos professores da Ilha de Fora no município de Curuçá/PA, como esta conexão pode ser concebida. Esta pesquisa é de caráter narrativo, utiliza-se a pesquisa-formação como guia e, portanto, também a Análise Textual Discursiva de Moraes e Galiazzi (2005) como sustento metodológico de análise. Os pensamentos ancoram-se nos teóricos Morin (2001), Santos (2007), Silva (2010) e Almeida (2017) os quais trabalham com a urgência de conhecer esse sujeito em sua complexidade inerente, voltando seus olhares tanto para o campo científico como para o da tradição; além da discussão de uma formação holística docente a partir da visão da Nóvoa (1994) e Imbernón (2011). Assim, ao mirarmos o ensino de ciências através do saber científico e da tradição, é possível romper a visão padronizada da ciência, o que proporciona um marco importante nos cursos de formação de professores na educação do campo na perspectiva dos espaços não formais de ensino.
\end{abstract}

Palavras-chave: Formação de professores. Educação do campo. Espaços não formais de ensino.

\begin{abstract}
This article aims to understand how non-formal learning spaces can contribute to the linking of scientific knowledge and tradition to the training of teachers who educate in the field in the elementary teaching. It is sought to understand and reflect, through narratives of teachers of Ilha de Fora at Curuçá/PA, how this connection can be conceived. This research is narrative, using the researchtraining as a guide and, therefore, also the Discursive Textual Analysis of Moraes and Galiazzi (2005) as methodological support for analysis. My baseline is the theorists Morin (2001), Santos (2007), Silva (2010) and Almeida (2017) who work with the urgency of knowing this subject in its inherent complexity, turning their eyes both to the scientific field and to that of tradition; besides the discussion of a holistic teacher training from the vision of Nóvoa (1994) and Imbernón (2011). Thus, by targeting the teaching of science through scientific knowledge and tradition, it is possible to break the standardized view of science which provides an important milestone in teacher training courses in the field education from the perspective of non-formal teaching spaces.
\end{abstract}

Keywords: Teacher training. Rural education. Non-formal learning spaces.

Submetido em: 11.12 .2019

Aprovado em: 17.04 .2020

\footnotetext{
${ }^{1}$ Esse trabalho é um recorte de minha proposta de tese de doutoramento

${ }^{2}$ Doutoranda do Programa de Pós-Graduação em Ciências e Matemática na linha de pesquisa em educação em Ciência. E-mail: veruschkamelo@gmail.com

3 Doutora em Ciências Sociais - Antropologia - Minha Orientadora de doutorado (PPGECM/IEMCI) Universidade Federal do Pará - ariadne@ufpa.br
} 


\section{INTRODUÇÃO}

A educação do campo vem ao longo dos anos tentando firmar um diálogo de ensino aprendizagem que possibilite um olhar diferenciado para esses povos (CALDART, 2002; SOUZA, 2008; FERNANDEZ, 2006). No presente artigo, tentamos uma conexão entre os saberes científicos e os saberes da tradição por meio de um espaço não formal de ensino para que esse entendimento se dê de maneira dialógica. Dessa forma, pensar na formação de professores que contemplem uma reflexão-ação a partir dessas discussões faz-se necessário. Uma vez que os saberes da experiência professoral adentram os espaços formais de ensino (escola) por intermédio dos professores ribeirinhos, trazendo toda uma gama de saberes da tradição mediante sua educação familiar e comunitária.

O contexto de nossa pesquisa é a Ilha de Fora, localizada no município de Curuçá. Essa ilha possui $50 \mathrm{~km}^{2}$ é cercada por braços de oceano e possui parte de seu território uma unidade de conservação de uso sustentável ${ }^{4}$ (UC), concebida com o nome de Reserva Marinha Extrativista Mãe Grande. Esta reserva, criada no ano de 2002, tem 278,6 km², e foi sancionada pelo Decreto Federal de 20 de maio de 2002. Concebemos essa ilha como um espaço não formal de ensino, que vem a ser todo aquele espaço em que práticas educacionais intencionadas podem ocorrer (JACOBUCCI, 2008).

Para Gohn (2006), a educação nesse ambiente não formal de ensino, não carrega ranços de uma organização escolarizada, com uma disposição de idade, conteúdo, espaço delimitados. Esta autora ressalta dois tipos de espaços não formais: os espaços institucionalizados, que são os com planejamento e estrutura física; e os espaços não institucionalizados que não dispõe de uma estrutura preparada para determinados fins, contudo, bem planejado e utilizado, poderá se tornar um espaço espontâneo, motivador e educativo, que é o espaço de onde falamos, chamada Ilha de Fora.

Assim sendo, o objetivo nesse texto, é compreender e refletir a partir das narrativas dos professores da Ilha de Fora no município de Curuçá. Como esta conexão pode ser concebida, uma vez que as suas formações se deram em espaços diferenciados dos seus campos de trabalhos docentes. Na perspectiva de Morin (2001) e Santos (2007), deve haver diálogo entre seres humanos para que haja uma compreensão mútua. E para que haja esse

\footnotetext{
${ }^{4}$ UCs de Uso Sustentável, a conservação da natureza é aliada ao uso de parcela de seus recursos ambientais, desde que a continuidade da biodiversidade e dos processos naturais da área sejam garantidas. http://www.semace.ce.gov.br/monitoramento/areas-naturais-protegidas/praias/. Acesso em: 07/08/2018.
} 
diálogo, Silva (2010) e Almeida (2017) apostam com veemência na conexão desses saberes científicos-tradição para uma leitura mais holística do saber fazer docente.

Assim, para alcançar nossas proposições, nos ancoramos na pesquisa narrativa por entender que por meio dos relatos dos professores suas narrativas trazem inúmeras informações que podem contribuir para percebermos como as propostas de formação docente estão próximas ou distantes dos espaços de docência dos alunos-professores.

Os espaços de formação docente são espaços que devem fomentar discussões, reflexões e propiciar diálogos entre os saberes científicos e da tradição, uma vez que a educação de formadores para a educação campesina necessita estar imbricada a partir das perspectivas dos sujeitos que vivem e atuam nesses espaços (temporalidade, saberes, entre outros).

De acordo com a Lei de Diretrizes e Bases de 1996 (LDB 9394/96) que preconiza no Art. 28 que,

$\mathrm{Na}$ oferta de educação básica para a população rural, os sistemas de ensino promoverão as adaptações necessárias à sua adequação às peculiaridades da vida rural e de cada região, especialmente: I - conteúdos curriculares e metodologias apropriadas às reais necessidades e interesses dos alunos da zona rural.

Dessa forma a LDB 9394/96 (2018) garante aos estudantes um amparo legal, que atenda às suas peculiaridades, ou seja, as suas especificidades precisam ser garantidas e dessa forma os conteúdos curriculares necessitam dialogar com os saberes advindos dessas comunidades. No entanto, segundo Caldart (2002, p. 22) os professores necessitam ser preparados para serem os sujeitos destas transformações. Caso contrário, esses professores não atenderão irão contextualizar o ensino. E dessa forma, o saber que será propagado será o saber científico.

Além disso, a LDB 9394/96 (2018) preconiza que os docentes devem colaborar com as atividades de articulação da escola com as famílias e a comunidade artigo 13. No entanto precisamos compreender se esta legalização realmente alcança os espaços de docência, uma vez que nos relatos das professoras o distanciamento entre esses saberes já se inicia dentro dos espaços formativos nas universidades.

De acordo com a LDB 9394/96 (2018) no artigo 43 em que, fala sobre as finalidades do ensino superior, destaco os três incisos a seguir, por conter em seu interior de maneira clara o entrelaçamento entre o científico e o cultural:

III - incentivar o trabalho de pesquisa e investigação científica, visando o desenvolvimento da ciência e da tecnologia e da criação e difusão da cultura, e, 
desse modo, desenvolver o entendimento do homem e do meio em que vive. (grifo nosso).

IV - promover a divulgação de conhecimentos culturais, científicos e técnicos que constituem patrimônio da humanidade e comunicar o saber através do ensino, de publicações ou de outras formas de comunicação. (grifo nosso).

Diante desse contexto, há urgência em colocarmos em prática discussões que possibilitem transitar entre a Academia e as escolas onde nossos docentes trabalham. Esses espaços são, e estão vivos de interações, pois os docentes além de terem o conhecimento científico também trazem na sua bagagem os saberes da tradição uma vez que são oriundos desses espaços e necessitam fomentar um diálogo entre esses saberes para que eles e seus alunos utilizem os saberes que vem de ambos os lados. Destarte, pensamos em uma metodologia que nos permitisse compreender o professor que atua nesse espaço.

\section{METODOLOGIA}

A presente pesquisa é de modalidade narrativa, por entender que estas são auto formadoras dos professores, de acordo com Josso (2004), trazem uma gama de elementos que podem levar os professores a se autocompreenderem, dessa forma entenderem os seus espaços formativos. Assim, utilizamos a pesquisa-formação que concebe a formação enquanto contínuo. Veremos a seguir:

\footnotetext{
Contribui para a formação dos participantes no plano das aprendizagens reflexivas e interpretativas, e situa-se em seu percurso de vida como um momento de questionamento retroativo e prospectivo sobre seu(s) projeto(s) de vida e sua(s) demanda(s) de formação atual. (JOSSO,2007, p. 421)
}

A pesquisa foi trabalhada com três professoras dos anos iniciais da educação básica, que trabalham como professoras na localidade de Ilha de Fora. A pesquisa passou por três momentos: 1) apresentação da professora formadora, assim como as expectativas e interesses de cada uma delas e a intenção da pesquisadora; 2) as três professoras contaram suas experiências formativas por meio de áudio, sendo que, cada áudio teve uma duração de trinta minutos; 3) logo após as narrativas individuais elas passaram para os relatos no grupo, falando sobre as suas experiências formativas. Em seguida buscamos na Análise Textual Discursiva de Moraes e Galiazzi (2005) um sustento metodológico de análise, no primeiro momento fizemos a unitarização dos relatos. De acordo com Moraes e Galiazzi (2007, p. 132), unitarizar , "É interpretar e isolar ideias de sentido sobre a temática investigada. Compõe leitura sensível, atenta e cuidadosa dos textos e/ou discursos dos sujeitos da 
pesquisa, momento no qual o investigador em Educação não pode deixar de assumir suas interpretações".

Em seguida fizemos a categorização, ou seja, a explicitação das categorias acontece por intermédio do retorno cíclico às unidades de análise, no intuito da construção gradativa do significado de cada categoria (MORAES, 2005). Dessa forma finalmente chegamos ao conjunto de textos derivados dessas análises textuais denominadas por Moraes e Galiazzi de metatexto.

\title{
2 RESULTADO E DISCUSSÃO
}

Recorrendo a Análise Textual Discursiva (MORAES e GALIAZZI, 2005), emergiu um eixo de análise. A esse primeiro eixo, denominamos de espaço formativo distante do contexto de profissão. A pesquisa formação traz a oportunidade do professor "olhar para si" mediante aos seus relatos e trocas de experiências entre as professoras. O tal olhar para si, também vem à memória as dificuldades encontradas para garantirem sua formação contínua:

\begin{abstract}
A saída para cursar o magistério (Projeto Gavião) ${ }^{5}$ era necessário pois, caso contrário eu não poderia mais lecionar as crianças. Eu só tinha o ensino fundamental maior ( $5^{\mathrm{a}}$ à $8^{\mathrm{a}}$ série) e de acordo com a Secretaria Municipal de Educação eu precisava ter no mínimo o magistério para continuar dando aula para as minhas crianças. Então eu percorria nos meses de férias todos os dias o mesmo trajeto. Percorria os sete quilômetros pensando nas dificuldades que eu passava para poder estudar. Aí eu chegava até a ponte e atravessava de barco para a cidade (Curuçá) e chegar até a escola. (NEIDE, 2015, grifos nossos).
\end{abstract}

Quando eu terminei o magistério eu não tinha muita escolha, eu terminei o magistério (Ensino Médio) em noventa e três quando minha mulher estava gravida e nessa época eu não tinha muita escolha e também não tinha dinheiro para ir para outro canto. Nessa época, aqui em Curuçá, só tinha o magistério, e destaca que fez não foi por escolha própria, pois só tinha o magistério e todos queriam cursá-lo. Só agora estou concluindo meu nível superior com a ajuda do governo no PARFOR $^{6}$, eu já estou terminando o nível superior em Ciências Naturais". (RENATA, 2015, grifos nossos).

Eu tinha o curso de magistério por não ter outra opção, mas quando passei no concurso para ser professora das séries iniciais, resolvi me dedicar de corpo e alma para poder ensinar tudo o que eu acho correto. "Todo dia para mim é um desafio que a gente vai aprendendo a cada dia e aprendendo também com os alunos" (NAYANE, 2015).

O processo de busca por uma formação profissional, nem sempre condiz com o que os professores almejam para si, as dificuldades passadas em busca dessa formação, deixam marcas significativas em suas experiências de vida e profissão. Pois, apesar de alguns não

\footnotetext{
${ }^{5}$ O projeto Gavião é criado a partir desta resolução. No estado do Pará é desenvolvido pela UFPA, sob a coordenação da Pró-Reitoria de Extensão.

${ }^{6}$ Programa do governo federal.
} 
terem tido a opção profissional, tem engajamento para quererem uma educação digna. Nos relatos, as professoras afirmam como seus contextos de formação profissional afetam o seu saber fazer docente. E o quanto o espaço não formal (Ilha de Fora) está imbricado nos seus relatos dessa profissão:

No magistério nós discutíamos sobre como ensinar as crianças, aquela parte de psicologia. Mas, nunca entrou em discussão a localidade em que vivemos e muito menos sobre os conhecimentos que a gente traz da nossa vivência na comunidade (NEIDE,2015).

Ninguém nunca trabalhou na universidade com os saberes que a gente conhece no nosso cotidiano, que trazemos dos nossos pais e avôs e avós. Eles trabalham superficialmente (Renata, 2015).

Para Imbernón (2011, p. 14), há uma necessária redefinição da docência como profissão, pois na contemporaneidade necessitamos ter uma visão holística do processo educativo, uma vez que, a profissão exerce outras funções: a motivação, a luta contra a exclusão social, a participação, a animação de grupos, as relações com estruturas sociais e com a comunidade. É claro que tudo isso requer uma nova formação: inicial e permanente.

A professora Nayane relata que,

Nunca discuti, esses saberes na universidade, essas discussões iniciaram nas Jornadas Pedagógicas no município, nos encontros com os colegas, que relatamos sobre nossas dificuldades. Sempre os conteúdos de ciências são dos livros didáticos e nunca entra em discussão o que nós aprendemos com nossos pais e avós.

Uma educação do campo deve realmente ser construída com a coletividade, uma vez que a comunidade é parceira da educação escolarizada dos filhos, mas, também não abre mão dos saberes que são repassados entre eles. Vale ressaltar que, a Ilha de Fora, enquanto espaço não formal de ensino possibilita o diálogo entre os saberes científicos e os saberes da tradição. Uma vez que, essas extensões de terras, são e estão ocupados por moradores que convivem harmoniosamente , utilizando as matas e florestas para suas plantações, caça e pesca para sua alimentação, e retirando frutos, folhas e cascas de arvores para utilizar de diversas maneiras (alimentação, remédio, entre outros). Esse espaço não formal de ensino deve ser discutido dentro dos limites de formação docente, a fim de possibilitar aos professores novos olhares para as suas comunidades, revendo conceitos, tanto dos professores, quanto dos alunos.

\section{CONSIDERAÇÕES FINAIS}

Refletir sobre a possibilidade de diálogo entre os saberes da tradição, formação docente campesina e espaços não formais de atuação se faz necessário uma vez que esses 
espaços amazônicos possibilitam uma interação diária com a comunidade, pois é com ele e a partir dele que a vida na comunidade acontece. A busca pelo alimento vem dos rios, manguezais e floresta (peixe, caranguejo, camarão, mexilhão, entre outros) dá-se dentro desse espaço, as plantações de mandioca, por exemplo, também são feitas na floresta. Também é da floresta que vem o remédio (plantas, ervas, cascas, entre outros). Assim, o saber da Tradição encontra-se presente dentro das comunidades a partir de cada espaço narrado anteriormente (mar, os rios, mangue, as florestas) ou seja, os seus saberes da Tradição se fazem presente na sua sobrevivência diária, na compreensão do seu mundo.

Portanto, ao mirarmos para esse espaço como catalisador de um ensino de Ciências em que os espaços de ensino dialoguem, também se cria novos percursos formativos, primeiro que, a ciência desta forma rompe com a visão estandardizada que é o saber cientifico, e cria conexões com para trabalharmos também os saberes da tradição. O ensino de Ciências necessita contemplar a complexidade da sociedade em que vivemos e precisa cultivar a cidadania, conectar homem-sociedade-meio ambiente natural.

Segundo, que a formação docente campesina necessita ser discutida para acompanhar as mudanças sociais, educativas e planetárias. Portanto, a formação docente deverá ofertar elementos teóricos, metodológicos, curricular, entre outros, aos professores a fim de, auxiliálos na construção de sua prática pedagógica. Desse modo, ao apresentarmos como objetivo compreender como a conexão de saberes pode ser concebida, uma vez que as formações dos professores se deram em espaços diferenciados dos seus campos de trabalho docente, faz com que, os professores, ao refletirem sobre o seu papel frente a esses desafios educativos os guiem a uma reflexão-ação, sobre sua própria prática.

Terceiro, que o espaço de atuação docente necessita ser ampliado, principalmente se a escola estiver inserida em um contexto sociobiodiversidade. Desta forma, oportunizar aos professores a trabalharem o ensino de ciências nos seus espaços de vida e atuação docente nos permite perceber a importância e contribuição que emergem desses espaços conectados a educação. Assim, compreendemos que o espaço não formal de ensino vem no sentido de contribuir como um amalgama de saberes em que irá interligar o professor ao seu espaço de vivencia e atuação docente, ou seja, construindo desta forma uma ponte entre universidadeprofessor-espaço de atuação docente.

Precisamos romper com a concepção de que só a educação formal (escola), o saber científico consiga contribuir com o processo ensino aprendizagem o espaço não formal de ensino por meio dos saberes da tradição também favorece a percepção, interação e conhecimento (JACOBUCCI, 2008; PIZA, FACHÍN-TERÁN, 2010). Desta forma, 
favoreceremos uma formação docente fortalecendo desta forma a relação afetiva, cognitiva e identitária dos professores conectando o saber científico com os saberes de suas comunidades.

\section{REFERÊNCIAS}

ALMEIDA, Maria da Conceição. Complexidade, saberes científicos, saberes da tradição. São Paulo: Livraria da Física, 2017.

BRASIL. Ministério da Educação. Diretrizes operacionais para a educação básica nas escolas do campo: CNE. Resolução CNE/CEB 1/2002. Diário Oficial da União, Brasília, DF: 2002.

. LDB: Lei de diretrizes e bases da educação nacional. 2. Ed.- Brasília: Senado Federal, Coordenações de Edições Técnicas, 2018.

CALDART, Roseli Salete. Por uma educação do campo: traços de uma identidade em construção. In: KOLLING. E. J; CERIOLI. P. R; CALDART. R. S. Educação do campo: identidade e políticas públicas. Brasília, DF: Articulação Nacional por uma educação do campo, 2002.

FERNANDEZ, F. S. El aprendizaje fuera de la escuela: tradición del passado y desafio para el futuro. Madrid: Ediciones Académicas, 2006.

GOHN, Maria da Glória. Educação não-formal na pedagogia social. [S. 1.: s. n.], 2006.

IMBERNÓN, Francisco. Formação docente e profissional: formar-se para a mudança e a incerteza. São Paulo: Cortez, 2011.

JACOBUCCI, Daniela Franco Carvalho. Contribuições dos espaços não-formais de educação para a formação da cultura científica. Em Extensão, Uberlândia, v. 7, p. 55-66, 2008.

JOSSO, Marie Christine. Experiências de vida e formação. São Paulo: Cortez, 2004.

A transformação de si a partir da narração de histórias de vida. Educação. Porto Alegre/RS, ano XXX, v. 63, n. 3, p. 413-438, set./dez. 2007.

MORAES, Roque; GALIAZZI, Maria do Carmo. Análise textual discursiva. Ijuí: Unijuí, 2007.

MORIN, Edgar. A religação dos saberes: o desafio do século XXI. Rio de Janeiro: Bertrand Brasil, 2001.

NÓVOA, Antônio. (Coord.). Os professores e sua formação. Lisboa: Dom Quixote, 1994.

PIZA, A. A. P. O ensino de ciências e a conservação dos recursos hídricos: uma proposta metodológica usando um espaço não formal. 141f. 2010. Universidade do Estado do Amazonas (Dissertação de Mestrado 2010. Universidade do Estado do Amazonas 
(Dissertação de Mestrado Profissionalizante). Programa de Pós-Graduação em Educação e Ensino de Ciências na Amazônia. Manaus: PPGEECA, 2010.

SANTOS, Boaventura Sousa. Renovar a teoria crítica e reinventar a emancipação social. São Paulo: Boitempo Editorial, 2007.

SILVA, Marcia Regina Farias. Ciência, natureza e sociedade: diálogo entre saberes. São Paulo: Livraria da Física, 2010.

SOUZA, Selma Maria Ferreira de. Saberes Docentes, Saberes Indígenas: um estudo de caso sobre o ensino de ciência entre o povo Xukuru do Ororubá. Dissertação de Mestrado. Universidade Federal Rural de Pernambuco, 2008, 122p. 